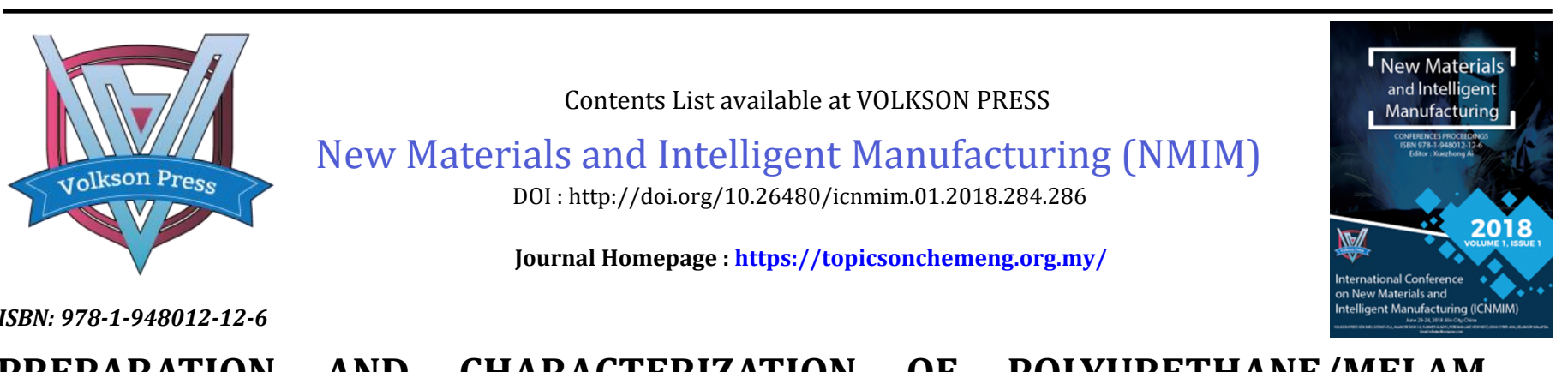

\title{
PREPARATION AND CHARACTERIZATION OF POLYURETHANE/MELAM INE INTERPENETRATING POLYMER NETWORK FOAMS
}

\author{
Shanshan Yao, Liu Feng, Fanlong Jin* \\ Department of Polymer Materials, Jilin Institute of Chemical Technology, Jilin City 132022, P. R. China \\ *Corresponding Author Email: jinfanlong@163.com
}

This is an open access article distributed under the Creative Commons Attribution License, which permits unrestricted use, distribution, and reproduction in any medium, provided the original work is properly cited.

\section{ARTICLE DETAILS}

\section{Article History:}

Received 26 June 2018 Accepted 2 July 2018

Available online 1 August 2018

\begin{abstract}
Polyurethane (PU)/melamine formaldehyde resin (MF) interpenetrating polymer network (IPN) foams were prepared by synchronous polymerization with MF and PU as raw materials. The effects of PU content on the apparent density, mechanical properties, and morphology of MF/PU IPN foams were investigated. The results showed that the apparent density and compressive strength of PU/MF IPN foams increased significantly with increasing PU content. Scanning electron microscope (SEM) showed that the pore structure of the foams changed
\end{abstract} little when the PU content was increased.

KEYWORDS

melamine, polyurethane, interpenetrating polymer networks, apparent density, mechanical properties.

\section{INTRODUCTION}

Melamine formaldehyde resin (MF) is a kind of polymer containing triazine ring which is formed by condensation reaction of melamine and formaldehyde solution after hydroxy methylation. Melamine is a common flame retardant because it releases a large amount of nitrogen after heat decomposition. MF foams are mainly three-dimensional network structure. This foam plastic has the characteristics of low density, good mechanical properties, excellent sound absorption, and excellent flame retardancy. Thus, it has great application prospect in industry, aviation field, and defense force [1-5]. However, due to the fact that MF foams contain a large number of three-dimensional network-like configurations composed of a large number of rigid triazine ring skeletons, the molecular interior has a small deformability, poor toughness, and low compressive strength, which can easily be pulverized when compressed. Thus, MF foams are limited in many areas. In recent years, the research on MF foams is mainly about the modification of its mechanical and thermal properties. The methods of modification include chemical modification and physical modification $[6,7]$.

Polyurethane (PU) foam is a polymer formed by the reaction of isocyanate with polyol. Its chain contains a large number of flexible structures, so it has excellent properties such as relatively light weight, heat insulation, sound absorption, shock absorption, insulation, high specific strength, and high flexibility $[8,9]$. However, the application of neat rigid PU foams has been restricted because of their high thermal expansion coefficient and low rigidity at high temperatures. One approach to improve the material properties is the introduction of a second reactive polymer into the PU reaction to compensate for the deficiencies of the existing material. This approach essentially produces an IPN $[10,11]$. In this work, PU/MF IPN foams were prepared by synchronous polymerization, and the effects of PU content on the apparent density, mechanical properties, and morphology of the foams were investigated.

\section{EXPERIMENTAL}

Table 1 shows materials used in this study.
Table 1: Experimental drugs

\begin{tabular}{|c|c|c|}
\hline Reagent name & $\begin{array}{l}\text { Specificati } \\
\text { on }\end{array}$ & Manufacturer \\
\hline Melamine & AR & $\begin{array}{lll}\text { Tianjin } & \text { Kenuo } & \text { Minimide } \\
\text { Chemical Co., Ltd. } & \end{array}$ \\
\hline $\begin{array}{l}\text { Formaldehyde } \\
\text { solution }\end{array}$ & $37 \%$ aq & $\begin{array}{l}\text { Liaoning QuanRui Reagent Co., } \\
\text { Ltd }\end{array}$ \\
\hline Dicyanodiamide & AR & $\begin{array}{l}\text { Tianjin DaMao Chemical Reagent } \\
\text { Co., Ltd }\end{array}$ \\
\hline Ethylene glycol & AR & $\begin{array}{l}\text { Tianjin DaMao Chemical Reagent } \\
\text { Co., Ltd }\end{array}$ \\
\hline Caustic soda & AR & $\begin{array}{l}\text { Tianjin DaMao Chemical Reagent } \\
\text { Co., Ltd }\end{array}$ \\
\hline Formic acid & AR & $\begin{array}{l}\text { Tianjin DaMao Chemical Reagent } \\
\text { Co., Ltd }\end{array}$ \\
\hline n-Pentane & AR & $\begin{array}{l}\text { Tianjin DaMao Chemical Reagent } \\
\text { Co., Ltd }\end{array}$ \\
\hline OP-10 & $\mathrm{CP}$ & $\begin{array}{l}\text { Tianjin DaMao Chemical Reagent } \\
\text { Co., Ltd }\end{array}$ \\
\hline Polyether glycol & (330) GR & $\begin{array}{l}\text { Changzhou Central Asia } \\
\text { Chemical Co., Ltd }\end{array}$ \\
\hline $\begin{array}{l}\text { Polyaryl } \\
\text { polymethylene } \\
\text { isocyanate }\end{array}$ & GR & Wanhua Chemical Group Co., Ltd \\
\hline Dibutyltin dilaurate & GR & $\begin{array}{l}\text { Tianjin YongDa Chemical } \\
\text { Reagent Co., Ltd }\end{array}$ \\
\hline
\end{tabular}

Table 2 shows analytical test instruments.

Table 2: Analytical test instruments

\begin{tabular}{|lcl|}
\hline Instrument name & Model & Manufacturer \\
\hline $\begin{array}{l}\text { Universal mechanic } \\
\text { al testing machine }\end{array}$ & WDW3010 & $\begin{array}{l}\text { Changchun Kexin Test instrument } \\
\text { Co., Ltd }\end{array}$ \\
$\begin{array}{l}\text { Field } \\
\text { emission scanning } \\
\text { electron microscopy }\end{array}$ & S8000 & Japan Hitachi Co., Ltd. \\
\hline
\end{tabular}


Preparation of MF resin : Appropriate melamine and formaldehyde solution were mixed and heated to $80{ }^{\circ} \mathrm{C}$. The $\mathrm{pH}$ of the mixture was adjusted to 8-9 using a concentration of $2 \mathrm{~mol} / \mathrm{L} \mathrm{NaOH}$ solution. At the same time, a spot of glycol and dicyandiamide were added, heated to 90 ${ }^{\circ} \mathrm{C}$, reacted for $1.5 \mathrm{~h}$, and cooled the discharge.

Preparation of PU/MF IPN foams : First, the MF resin and foam stabilizer were added to a beaker and stirred for $5 \mathrm{~min}$, followed by the addition of formic acid and n-pentane, then stirred well and foamed. Second, quantitative polyether polyol, isocyanate, OP-10, and foam stabilizer were added into the paper cup and stirred for 3 min to obtain a uniform yellowish liquid. Last, the PU prepolymer was added to MF resin prefoams, in which PU and MF were mixed at a certain mass ratio. Water and n-pentane were added at the same time. The PU/MF IPN foams were prepared by mechanical stirring for $30 \mathrm{~s}$ and then solidified at $70^{\circ} \mathrm{C}$ for 2

The foams were dried at $60^{\circ} \mathrm{C}$ for $72 \mathrm{~h}$ and cut into $5 \times 5 \times 5 \mathrm{~mm}^{3}$ samples. Based on the density formula:

$\rho=m / V \times 10^{6}$

where $\rho$ is the apparent density (in $\mathrm{kg} / \mathrm{m}^{3}$ ), $\mathrm{m}$ is the mass of the sample (in $\mathrm{g}$ ), and $\mathrm{V}$ is the volume of the sample (in $\mathrm{mm}^{3}$ ).

According to the requirements of GB/T 8813-2008, the static compression properties of the foams were measured by using a universal mechanical tester. The foam was cut into a cube with a specification of $50 \times 50 \times 50 \mathrm{~mm}^{3}$, and the speed was $2.5 \mathrm{~mm} / \mathrm{min}$. Based on the compression strength formula, the calculation is as follows:

$$
\sigma=\frac{F}{A} \times 10^{3}
$$

where $\sigma$ is the compressive strength (in $\mathrm{kPa}$ ), $\mathrm{F}$ is the maximum compression force (in $\mathrm{N}$ ), and $\mathrm{A}$ is the initial cross-sectional area $\left(\mathrm{mm}^{2}\right)$.

\section{RESULTS AND DISCUSSION}

The PU/MF IPN foams were prepared via a simultaneous IPN method. Figure 1 shows a schematic preparation diagram for PU/MF IPN.

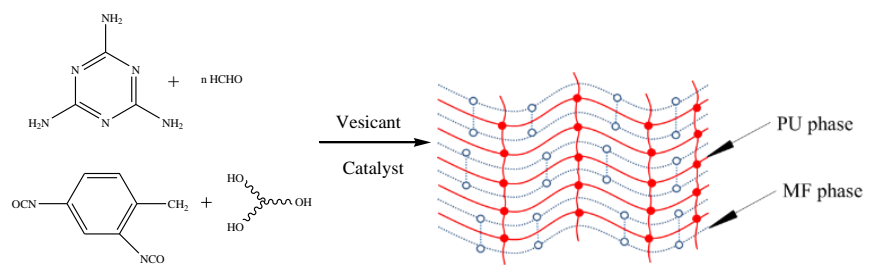

Figure 1: Schematic preparation diagram of PU/MF IPN.

The physical, mechanical, and morphologies of PU/MF IPN foams were investigated.

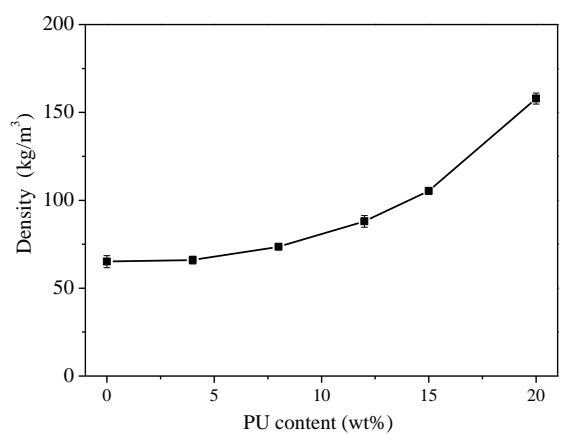

Figure 2: Effect of PU content on density of PU/MF IPN foams.

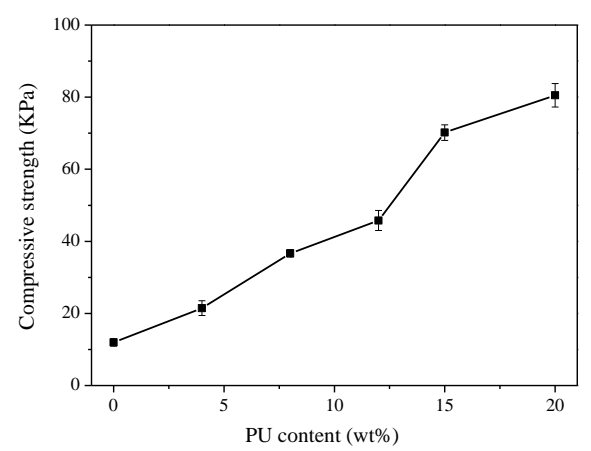

Figure 3: The relationship between the PU content and compressive strength.

Figure 2 shows the apparent density values of the PU/MF IPN foams as a function of the PU content. The density of the foams increased with the increase of PU content. The apparent density of pure MF foam was 65.1 $\mathrm{kg} / \mathrm{m}^{3}$, and the apparent density of foams was $157.9 \mathrm{~kg} / \mathrm{m}^{3}$ when PU content was $20 \mathrm{wt} \%$.

Figure 3 shows the relationship between compressive strength and PU content of PU/MF IPN foams. With the increase of PU content, the compressive strength of the foams increased significantly. The compressive strength of pure MF foam was $11.9 \mathrm{kPa}$, and the compressive strength of PU/MF IPN foam was $81.6 \mathrm{kPa}$ when PU content was $20 \mathrm{wt} \%$. Due to MF continuous phase, the addition of PU played a role in toughening. There were a large number of flexible segments in PU, which can be compatible with MF, thus effectively improved the mechanical strength of the foams. With the increase of PU content, the flexible structures in the foams increased gradually, absorbed more external stress, thus increased the compressive strength of the foams [12].

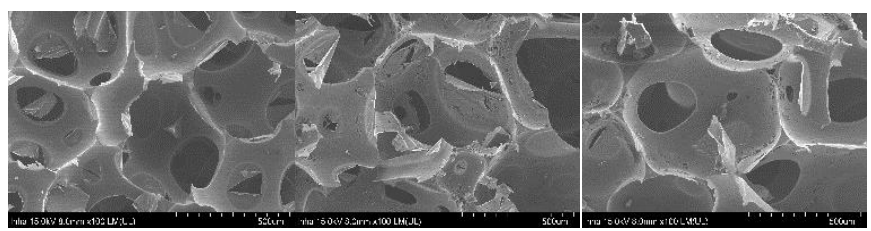

(a) MF

(b) $4 \mathrm{wt} \% \mathrm{PU}$

(c) 8 wt $\%$ PU

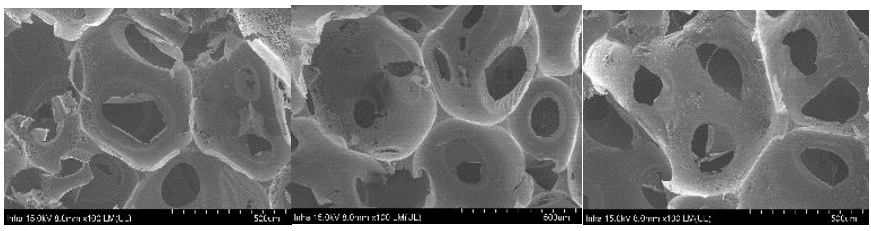

(d) $12 \mathrm{wt} \% \mathrm{PU}$

(e) 15 wt $\%$ PU

(f) $20 w t \% P U$

Figure 4: SEM micrographs of PU/MF IPN foams materials.

Figure 4 shows the SEM images of pure MF foam and PU/MF IPN foams with different PU content. The difference of pore size and shape can be determined by observing the cross section of PU/MF IPN foams. It can be seen from the diagram that the foam bubble was porous, and there existed a certain degree of rupture, and the bubble pore dispersion was more uniform. As shown in Figure 4(a), the foam structure of MF foam was open pore structure, each bubble pore had at least two pores or two failure surfaces, and most of the foam pores were shared by at least three structural units. With increasing the PU content, the foam pore changed little, and the degree of foam fragmentation decreased. It can be seen that the PU/MF IPN foams prepared by adding PU into MF reduces the friability of MF foams.

\section{CONCLUSION}

PU/MF IPN foams were prepared by synchronous polymerization. The density, compression strength, and morphology of the foams were characterized. The results showed that the density of IPN foams increased with the increase of PU content. The compressive strength of the foams increased from 11.9 to $80.6 \mathrm{kPa}$ when the PU content was increased from 
0 to $20 \mathrm{wt} \%$ due to the increase of flexible structure. The SEM images of the foams showed that the structure of foam hole had little changed and the degree of fracture of the foam hole was reduced.

\section{ACKNOWLEDGMENTS}

This work was supported by the project of Jilin Province (20180414018GH).

\section{REFERENCE}

[1] Sidhu, P., Muthusamy, S., Kannan, S. 2015. Melamine foam in Dentistry. International Journal of Dental Hygiene, 13 (4), 239-240.

[2] Yang, J.C., Cao, Z.J., Wang, Y.Z. 2015. Ammonium polyphosphatebased nanocoating for melamine foam towards high flame retardancy and anti-shrinkage in fire. Polymer, 66, 86-93.

[3] Wu, K., Song, L., Wang, Z. 2008. Microencapsulation of ammonium polyphosphate with PVA-melamine-formaldehyde resin and its flame retardance in polypropylene. Polymers for Advanced Technologies, 19 (12), 1914-1921.

[4] Wang, D., Zhang, X., Luo, S. 2013. Preparation and property analysis of melamine formaldehyde foam. Advances in Materials Physics and Chemistry, 2 (04), 63-69.

[5] Głowacz-Czerwonka, D. 2013. Polyurethane foams from melamine solutions in reactive solvents based on ethyl methyl ketone. Journal of Applied Polymer Science, 128 (5), 3465-3472.

[6] Park, B.D., Jeong, H.W. 2010. Cure kinetics of melamineformaldehyde resin/clay/cellulose nanocomposites. Journal of Industrial and Engineering Chemistry, 16 (3), 375-379.

[7] Hanafiah, M.M., Ali, M.Y.M., Aziz, N.I.H.A., John, A. 2017. Biogas production from agrowaste and effluents. Acta Chemica Malaysia, 1 (1), 13-15.

[8] Xu, Q., Zhai, H., Wang, G. 2015. Mechanism of smoke suppression by melamine in rigid polyurethane foam. Fire and Materials, 39 (3), 271-282.

[9] Saha, M.C., Kabir, M.E., Jeelani, S. 2008. Enhancement in thermal and mechanical properties of polyurethane foam infused with nanoparticles. Materials Science and Engineering: A, 479 (1), 213-222.

[10] Cai, Y., Liu, P., Hu, X. 2000. Microstructure-tensile properties relationships of polyurethane/poly (urethane-modified bismaleimidebismaleimide) interpenetrating polymer networks. Polymer, 41 (15), 5653-5660.

[11] Chen, S., Wang, Q., Wang, T. 2011. Hydroxy-terminated liquid nitrile rubber modified castor oil-based polyurethane/epoxy IPN composites: Damping, thermal and mechanical properties. Polymer Testing, 30 (7), 726-731.

[12] Jin, F.L., Feng, L., Si, Q.B., Soo, J.P. 2016. Physico-mechanical and fire properties of polyurethane/formaldehyde interpenetrating polymer network foams. Macromolecular Research, 24, 773-776.

\section{ABOUT THE AUTHORS}

Shanshan Yao was born on May 24, 1981, in Jilin, China, female, associate professor, she taught at Jilin Institute of Chemical Technology (JLICT), mainly engaged in the study of synthesis and modification of polymer materials. Professor Fanlong Jin was born on March 19, 1963, in Tumen city, China. He earned a Ph. D. from Chungbuk National University in 2005. He taught at Jilin Institute of Chemical Technology in China. His research areas are synthesis of biodegradable polymers, polymer blends, preparation of polymer-based composites and nanocomposites. 